\title{
Analysis of the Mortgage Value Evaluation of Construction in Progress
}

\author{
Zeng Dandan ${ }^{1,}$, , Chen Long ${ }^{2}$ \\ ${ }^{1}$ Major of Land Resource Management, Wuhan Donghu University, Wuhan, China, 430070 \\ ${ }^{2}$ Major of Land Planning, Wuhan Hongyufei Planning and Design Technology CO. LTD., Wuhan, China, \\ 430070
}

Keywords: Construction in Progress; Mortgage Value; Real Estate Assessment

\begin{abstract}
In the numerous industries of the national economy, the funds involved in real estate development are relatively large. However, at the current stage, the real estate developers in China have limited self-owned funds. Therefore, a large part of real estate developers uses project mortgages under construction as an important means of real estate project financing. Mortgage of construction in progress is of great significance for real estate developers to ease the tight funding chain and complete project construction on time. However, due to the fact that there are more uncertainties and more risks in construction in progress mortgages compared with existing mortgages, the evaluation of the mortgage value of construction-in-progress is particularly important. Based on the aforementioned consideration, this paper analyzes the risks in construction project mortgages, where the traditional valuation method to evaluate the mortgage value of projects under construction is used. Besides, a case of a project under construction in Xinshi Town, Baiyun District, Guangzhou City is presented in this study, to analyze the technical difficulties in actual value of the project under construction, and propose the corresponding countermeasures.
\end{abstract}

\section{Introduction}

With the growing development of the real estate industry, more and more real estate developers want to do as large development projects as possible. In 2016, there are a total of 131 real estate companies in China with sales of billions, of which market share is close to $50 \%$, and the amount of large-scale real estate development companies has already accounted for half of the real estate market. The financing channels of most real estate development companies at home and abroad come from bank loans, and most bank loans are issued on the basis of legal guarantees provided by borrowers or the third parties. At present, most real estate development companies in China can only apply for secured mortgage loans, and a common practice for real estate developers is to use projects under construction as collateral to finance banks.

This article through the analysis and discussion of the traditional real estate construction project mortgage value assessment, combined with assessment examples, to further improve the traditional valuation method. Through the rational setting of risk adjustment coefficient, the subjective component of the assessment process is expected to be reduced, which is of great significance for preventing risks, ensuring the financial security of financial institutions, and implementing financial financing effectively.

\section{Construction Engineering Mortgage Valuation Overview}

\subsection{The Definition of Real Estate Under Construction}

"Construction-in-progress" refers to real estate developers who want to obtain financing during the construction of real estate projects, ease the tension in the capital chain, and provide the unfinished real estate as collateral to banks to obtain loans [1]. The construction-in-progress referred to in this article is a narrow sense concept and refers to a state in which a real estate construction project is located from the start of construction to completion of completion acceptance. 


\subsection{The Meaning of mortgage value of construction in progress}

Mortgage of construction-in-progress refers to the fact that real estate developers mortgage the construction in progress to commercial banks in order to obtain bank loans during the development and construction of real estate projects [2]. Through this behavior, on the one hand, developers can ease funding constraints and obtain financial support to smoothly promote real estate development projects. On the other hand, construction in progress as collateral is also an effective precaution against commercial banks for risks.

\subsection{Mortgage valuation method for construction in progress}

Market comparison method, income method, cost method, and hypothetical development method are the four basic methods commonly used in real estate evaluation. The selection of appropriate valuation methods based on the characteristics of the valuation object and the different valuation purposes is the basic principle of real estate evaluation [3].

Hypothetical Development Method to Assess the Mortgage Value of Construction in Progress. The hypothetical development method can also be used when assessing the mortgage value of projects under construction. The technical thinking of the project under construction is based on a reasonable estimate of the construction period [4]. The value of the completed valuation object is first calculated and then deducted. Expenses, so as to obtain the market price of the appraisal object at the time of appraisal. Its calculation formula is:

Construction Project Valuation Value=Real estate value after completion of the renewal

$$
\begin{aligned}
& \text {-Construction cost-Continuation of management costs } \\
& \text {-Continuation of capital cost-Sales expense-Sales tax } \\
& \text {-Continued profit }
\end{aligned}
$$

Using Cost Method to Evaluate the Mortgage Value of Construction in Progress. When using cost method to assess the mortgage value of construction in progress, it is necessary to first obtain the acquisition cost of the land through the market comparison method or the reference land price coefficient amendment method, and then to obtain the value of the completed building part of the construction in progress through the replacement cost method. Then sum the two to get the total value of the project under construction [5]. Its calculation formula is:

$$
\begin{aligned}
\text { Total value of construction-in-process } & =\text { acquisition cost of land }+ \text { construction and installation costs } \\
& + \text { infrastructure supporting fees in red line }+ \text { up-front and professional fees } \\
& + \text { management fees }+ \text { investment interest }+ \text { sales expenses } \\
& + \text { sales tax }+ \text { development profits }
\end{aligned}
$$

\section{The procedural framework for the evaluation of mortgage value of construction in progress}

\subsection{Legal Requirements for the Evaluation of Mortgage Value of Construction in Progress}

At present, China's national norms and procedures related to the evaluation of the mortgage value of real-estate projects under construction [6] mainly include: "Law of the People's Republic of China on the Administration of Urban Real Estate", "Standards for the Valuation of Real Estate of the People's Republic of China" and "Land Management Law of the People's Republic of China". "The State of the People's Republic of China Standard Classification of Land Use", "Guidelines for Real Estate Mortgage Evaluation", "Measures for the Management of Urban Real Estate Mortgage" and so on.

The main basis for the writing of real estate mortgage valuation report for construction-inprogress projects is "Administrative Measures for Urban Real Estate Mortgage", "Guiding Opinion on Real Estate Mortgage Evaluation", and "Standard for Real Estate Appraisal of the People's Republic of China National Standard". 


\subsection{Procedures for assessing the value of mortgages under construction}

Generally speaking, from the time of acceptance of the valuation commission to the completion of the valuation report, the real estate valuation should be carried out according to the following procedure [7]. The flow chart is presented in Fig.1.

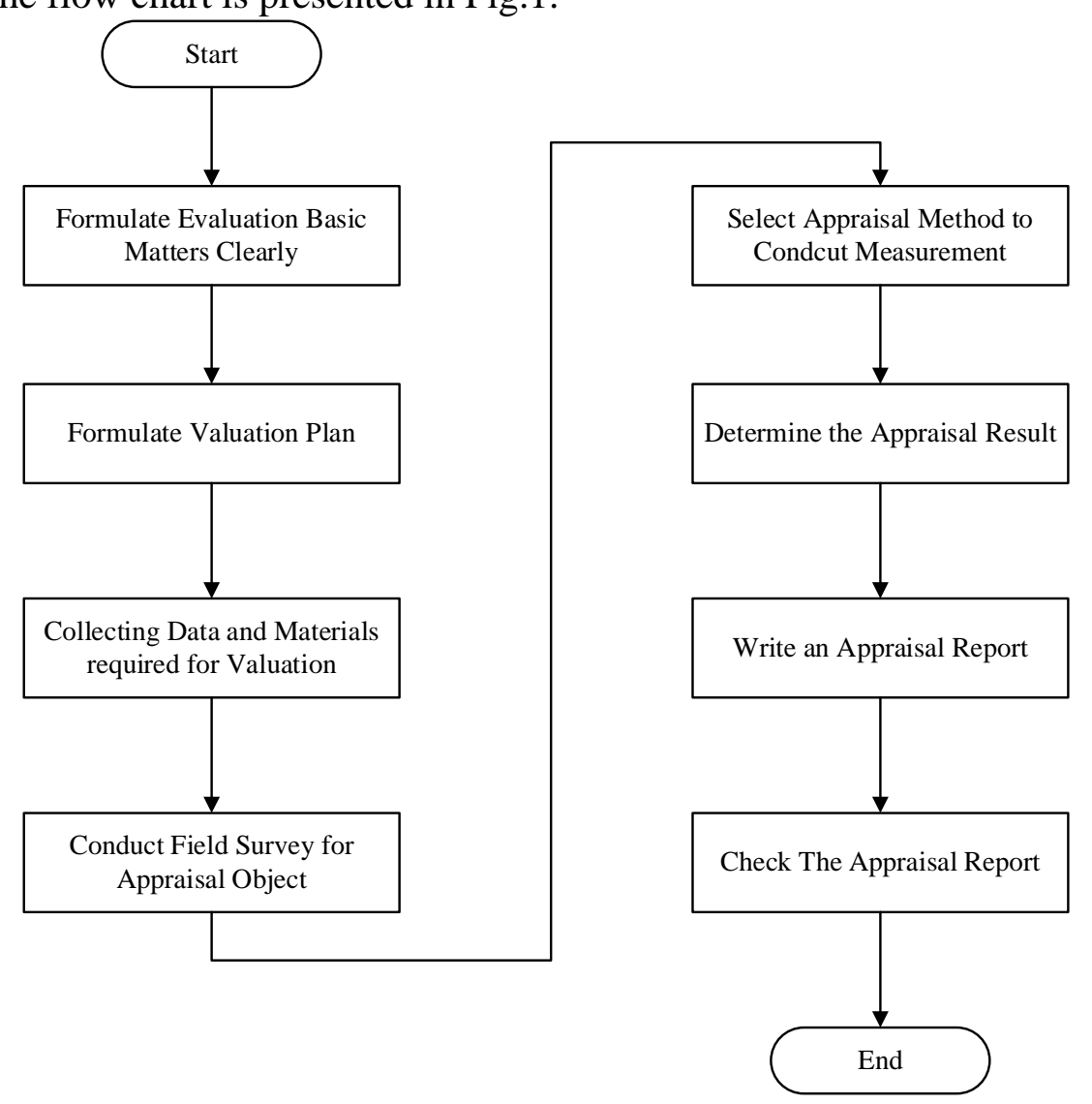

Fig.1 Valuation Procedure Flow Chart

\section{4. se Study of Construction Project Value Assessment}

\subsection{Case Introduction}

A project under construction in Xinshi Town, Baiyun District, Guangzhou City is located on the east side of one of the main highways in Guangzhou, on the west side of Yixin Road, and belongs to the Xinshi District of Baiyun District, Guangzhou City. The appraisal target is located on the east side of the Guangzhou Expressway, one of the main highways in Guangzhou. It is surrounded by Qifu Road, Yuncheng West Road, Baiyun Avenue South, and other roads, forming a dense surrounding road network with good traffic accessibility. The appraisal object is about 300 meters away from the bus stop of Yixin Road and has multiple public transportation lines such as 199, 420, 555 and 981. The traffic is convenient. The area where the appraisal target is located is the urban built-up area, and the infrastructure for water, electricity and gas is perfect. The time point for valuation of this valuation act is July 14, 2016. The purpose of the valuation of this valuation act is to provide a reference for the market value of the mortgage loan under construction.

\subsection{Case Assessment}

In this case, the cost method is used to assess the building value, and the surplus method is used to estimate the land value. According to the purpose of this valuation, the value of the appraisal object includes the pre-construction cost of the above-ground buildings and buildings, the cost of construction and installation, and the value of the land use rights.

Construction and installation cost. The cost of construction and installation engineering includes the cost of civil works and the cost of installation. The calculation is based on the unit project cost 
and construction cost index of various types of construction projects in the construction cost stations in Guangzhou.

Upfront costs. The preliminary costs include surveys, design fees, construction fees, construction supervision fees, and other professional fees, which are calculated based on relevant regulations and market conditions.

Tab.1 Valuation Object Value Calculation Table

\begin{tabular}{|c|c|c|c|c|}
\hline Number & Name & Calculation basis & $\begin{array}{c}\text { Take fee } \\
\text { (rate) }\end{array}$ & \\
\hline 1 & Design survey fee & 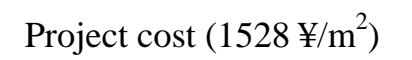 & & \\
\hline & & & $2 \%$ & $22.92 ¥ / \mathrm{m}^{2}$ \\
\hline 2 & Tender fee & Project cost $\left(1528 ¥ / \mathrm{m}^{2}\right)$ & & \\
\hline 3 & Engineering supervision fee & Project cost (1528 $\left.¥ / \mathrm{m}^{2}\right)$ & $1.00 \%$ & $15.28 ¥ / \mathrm{m}^{2}$ \\
\hline 4 & Urban infrastructure fee & Construction area & $10 ¥ / \mathrm{m}^{2}$ & $10 ¥ / \mathrm{m}^{2}$ \\
\hline 5 & $\begin{array}{l}\text { Construction unit management } \\
\text { costs }\end{array}$ & Project cost (1528 $\left.¥ / \mathrm{m}^{2}\right)$ & $2 \%$ & $30.5664 ¥ / \mathrm{m}^{2}$ \\
\hline 6 & Project costs & $1528 ¥ / \mathrm{m}^{2}$ & - & $1528 ¥ / \mathrm{m}^{2}$ \\
\hline 7 & Subtotal & - & - & $1606 ¥ / \mathrm{m}^{2}$ \\
\hline 8 & Depreciation of buildings & Building replacement cost & $30 \%$ & $482 ¥ / \mathrm{m}^{2}$ \\
\hline 9 & Building replacement value & - & - & $482 ¥ / \mathrm{m}^{2}$ \\
\hline
\end{tabular}

Tab.2 Land Use Rights Value

\begin{tabular}{ccc}
\hline \hline Number & Correction factor & Correction range \\
\hline 1 & Year Revision & 0.8388 \\
2 & Volume rate & 0.99 \\
3 & Status of the parcels & 1 \\
4 & Parcel area & 1 \\
5 & Five connections and one level situation & $-35 ¥ / \mathrm{m}^{2}$ \\
Benchmark land price & $8323 ¥ / \mathrm{m}^{2}$ & - \\
Parcel value & $6877 ¥ / \mathrm{m}^{2}$ & - \\
\hline \hline
\end{tabular}




\subsection{Analysis of Valuation Results}

Through a deep analysis of this valuation behavior, it is not difficult to find that there are many problems in this valuation act. There are many places that are not perfect enough, and there are many problems that are commonly found in traditional valuation practices.

(1) Failure to fully explain the construction quality of the project under construction. Although it was stated that the valuation target was started in 1993, due to various reasons, it was still unable to provide the completion acceptance certificate at the time of valuation. It was an idle building project that was idle for nearly 23 years. Therefore, the evaluation price in the above table shows the construction. The price part of the item only includes the pre-construction cost of the appraisal object, the construction and installation engineering fee and the management fee. However, no follow-up construction quality certification, or require the right holder to provide relevant construction quality certification instructions.

This practice will have a greater impact on the evaluation of the mortgage value of real estate projects under construction. If it is determined that there are serious problems in the construction quality of the projects under construction and it is impossible to continue the construction, the value of the buildings should be excluded in the assessment process. Instead, it needs to be considered. The cost of demolishing the building. The basic assessment of the technical route should be the evaluation target value $=$ value of land use rights - building demolition costs. If the construction quality is good and there is a possibility of renewed completion, the value of the building should be taken into account. The basic evaluation technique route at this time should be the evaluation target value $=$ value of land use rights + building value.

(2) In the evaluation of the mortgage value of real estate under construction, the valuation result obtained should be a valuation of the net value. That is, the total value of the valuation is deducted from the corresponding expenses, including various taxes, assessment fees, legal priority to be paid, and various deductions that the valuer should be aware of. However, the net value is not calculated in the text, but only the calculated total value is given. This is highly likely to cause undue evaluation results, making the assessment results deviate from the actual value of construction in progress.

(3) This assessment uses the cost method, in which the cost method is used to measure the value of the building and the benchmark land price revision method is used to measure the value of the land use rights. In the process of benchmark land price revision, there are no uniform standards for the selection of various parameters, and there are many uncertainties.

(4) This assessment still uses the traditional assessment method. It does not provide explanations and calculations for the realizable risks of construction-in-progress, which increases the risks of the mortgage-based value assessment of the projects under construction.

\subsection{Countermeasures to Promote Assessment of Projects Under Construction}

In this study, three countermeasures are provided to promote the assessment of projects under construction, which are presented as follows:

Guide appraisers to strengthen the study of engineering knowledge. At present, many appraisers have relatively little knowledge of construction engineering. This is in fact extremely unfavorable to the evaluation of the value of mortgages under construction and brings greater difficulties to the evaluation of the real estate value of projects under construction. Assessment agencies should actively organize assessment personnel to learn relevant knowledge of construction projects and strengthen the training and learning of business abilities. On the other hand, when assessing the mortgage value of projects under construction, the appraisal agency should also require the consigner to provide a corresponding construction project quality inspection report to be responsible for each valuation act [8].

Full consideration of various factors affecting liquidation. The liquidity of the construction-inprogress is affected by many factors, including its own conditions, rights and interests, market auctions, and external economic environment. When assessing the mortgage value of projects under construction, these conditions should be fully considered and reasonable risk factors for realization 
should be set [9].

Establish a risk coefficient adjustment model. For the evaluation of the mortgage value of construction in progress, in addition to the traditional theory and method of real estate appraisal, a risk coefficient adjustment model should also be established for the specificity of the project under construction [10].

There are many risks associated with the evaluation of the mortgage value of construction in progress, which mainly includes the following three types: project construction duration risk, engineering construction quality risk and architectural design change risk. For the above risks should be quantified, a risk adjustment model can be established through a simple weighted sum function to achieve the purpose of risk quantification.

\section{Conclusions}

In this study, by studying the relevant contents of the mortgage value assessment of the construction in progress, the theoretical source of traditional construction in-service mortgage value assessment and the technical route and ideas of traditional valuation are elaborated firstly. On this basis, the insufficiency of the theory and method of traditional construction in progress assessment is further analyzed, including the neglect of the quality certification, the verification of the realization ability and the risk quantification for the construction in progress, based on which the related solutions are proposed finally.

Mortgage of projects under construction is a very large research object, and this feature is not only reflected in the aspect of large amount of capital investment and social influence required by the real estate development industry, but also reflected in the aspect of many stakeholders involved in the evaluation of the mortgage value of construction in progress, including home buyers, developers, real estate market regulators, and financial institutions. The evaluation of the mortgage value of projects under construction is a very important part of the real estate development industry in China, which is of great significance in promoting the healthy development of the real estate industry and the steady advancement of real estate finance.

\section{References}

[1] Ferreira F A F, Santos S P. Comparing trade-off adjustments in credit risk analysis of mortgage loans using AHP, Delphi and MACBETH[J]. International Journal of Strategic Property Management, 2016, 20(1): 44-63.

[2] Shek D T L, Wu F K Y. The social indicators movement: Progress, paradigms, puzzles, promise and potential research directions[J]. Social Indicators Research, 2017: 1-16.

[3] Zhang H. The Research of the Private Enterprise Credit Evaluation System[J]. Journal of Residuals Science \& Technology, 2016, 13(8).

[4] Romanova A I, Afanasyeva A N, Mavlyautdinov A S, et al. Socio-economic aspects of mortgage lending for housing construction in Tatarstan[J]. International Journal of Economics and Financial Issues, 2016, 6(2S).

[5] LI Z, HE Q, ZHAO H U I F. Evaluation of Mortagage Value of Forestry Assets Based on the Monte Carlo Simulation[J]. Journal of Residuals Science \& Technology, 2016, 13(3).

[6] Ferreira F A F, Santos S P, Dias V M C. An AHP-based approach to credit risk evaluation of mortgage loans[J]. International Journal of Strategic Property Management, 2014, 18(1): 38-55.

[7] Hełdak M, Stacherzak A. Valuation of Residential Premises for the Purposes of Securing the Receivables of the Creditor in Poland[C]//IOP Conference Series: Materials Science and Engineering. IOP Publishing, 2017, 245(7): 072004.

[8] AF Ferreira F, P. Santos S, SE Marques C, et al. Assessing credit risk of mortgage lending using MACBETH: a methodological framework[J]. Management Decision, 2014, 52(2): 182-206. 
[9] Fernández-López X L, Coto-Millán P. From the boom to the collapse: A technical efficiency analysis of the Spanish construction industry during the financial crisis[J]. Construction Economics and Building, 2015, 15(1): 104-117.

[10] Nezhnikova E, Kashirin V, Davydova Y, et al. Methodology for determining the investment attractiveness of construction of high-rise buildings[C]//E3S Web of Conferences. EDP Sciences, 2018, 33: 03031. 